\title{
Educating nursing students in team conflict communication
}

\author{
Rosanne L. Hartman ${ }^{1}$, Alice L. Crume ${ }^{2}$ \\ 1. Department of Communication Studies, Canisius College, Buffalo, United States. 2. Department of Communication \\ Studies, Texas Tech University, Lubbock, Texas, United States.
}

Correspondence: Rosanne Hartman. Address: Department of Communication Studies, Canisius College, 318 Lyons Hall, 2001 Main Street, Buffalo, United States. Email: hartmanr@canisius.edu

Received: July 3, 2014

DOI : $10.5430 /$ jnep.v4n11p107

\begin{abstract}
Interdisciplinary health care teams are pivotal in creating and organizing the comprehensive care and treatment of patients. Health care teams providing comprehensive services create an integrative approach that focuses on open communication among members. One challenge when communicating in teams is recognizing and understanding the potential for conflict. Awareness of conflict and an understanding of communication behaviors leading to more competent conflict management will create higher quality team performance. Increasing communication competence leads to more cooperative sharing of information and provides the opportunity for practiced decision-making. Understanding the team process can be strengthened by educating future health care workers, especially nursing students. In doing so, nursing students will learn and practice how to manage team conflict. To create an educational curriculum in conflict processes and management, it is necessary to understand conceptions about the conflict process. As a result, curriculum design is based on needs identified from the research. Therefore, the purpose of this study is to examine individual perceptions that current nursing students have about conflict, strategies individuals use for conflict resolution, and what communication strategies are perceived as being competent for health care team conflict resolution. Based in social learning theory, the final outcome is to understand expectations about team conflict behaviors to create a framework to design educational programs in conflict management for nursing programs.
\end{abstract}

\section{Key words}

Conflict, Nursing education, Communication competence, Integrative health care teams, Interdisciplinary approach in health care, Students, Teaching methods, Conflict management

\section{I ntroduction}

Increasingly, interdisciplinary health care teams are the vehicle for delivering comprehensive treatment of health care for patients ${ }^{[1]}$. Such teams require new skills to work cooperatively together to deliver quality care. For example, health care team members must learn and practice ways in which to integrate information flow among members while keeping the focus on improving patient care. When interdisciplinary teams work well together, there is an increase of positive and measurable patient outcomes. Such teams design practices which integrate communication among members so that when these strategies are consistently practiced by team members, there are positive outcomes for practitioners and patients ${ }^{[2-4]}$. Health care teams that collaborate, have strong communication processes and skills, and have an understanding of conflict 
management processes are better able to perform and focus on the task ${ }^{[5]}$. Conversely, integrating patient care may impede team performance when there are poor communication practices leading to conflict among team members ${ }^{[2,6]}$. Therefore, it is imperative to become educated in communication processes and conflict management. However, there is little research on what content should be taught, how to teach it and how to assess the long term impact of educational programs in these areas.

Increasing communication competence when engaging in conflict leads to more cooperative sharing of information and better decision-making. Education and training that strengthens how people can work together in health care teams will improve conflict management and communication among members ${ }^{[7,8]}$. Curricular development for such education must begin with exposing personal perceptions about conflict, how conflict might enhance team performance and provide ways in which students practice conflict management skills. Therefore, the purpose of this paper is to examine perceptions about conflict and the conflict process, current strategies that are used for conflict resolution and communication strategies perceived as being competent during conflict. In understanding perceptions about conflict and communication behavior, there can be a baseline understanding of conflict that leads to curricular development that builds from that baseline.

\subsection{Communication competency and conflict}

One strategy for improving team communication and conflict management is in the understanding and practice of communication competency. Communication competency is the ability to interact flexibly with others by using communication strategies that are appropriate and effective for the context. Martin and Rubin ${ }^{[9]}$ describe the application of communication competency as having an understanding of what we believe our knowledge and skills are currently so that we are able to develop ways to increase our effectiveness. From this framework, it is important to understand one's current beliefs and behaviors about a process. Using current understanding as a baseline, we are able to increase knowledge and skills related to the communication competency, in this instance, conflict management.

Practicing communication competency becomes more challenging when in conflict situations. For example, health care teams are a combination of people in different roles, with diverse expectations, who have different levels of expertise, with power differentials based on expertise and who have disparate ideas for the team process ${ }^{[10]}$. These dynamics increase the potential for conflict and hinder decision-making therefore impacts patient care. Efforts should be made to educate health care professionals in conflict management practices and competent communication strategies related to conflict. However, little research has been done on conflict resolution and communication processes within interdisciplinary health care teams ${ }^{[11]}$.

One potential challenge facing any health care team is the recognition and understanding of potential conflict and competent communication behaviors to deal with such conflict. A team member's disposition about conflict impacts their initial response to conflict and how they enact conflict behaviors. For example, a negative disposition towards conflict itself may lead to a range of negative emotional responses and behaviors by team members. These negative responses are not conducive for conflict facilitation. Further, an individual's conflict style leads them to choose certain conflict strategies and tactics consistently in initial conflict engagement regardless of the context or relationship ${ }^{[12]}$. Therefore, educating health care professionals in their understanding of conflict must first begin with understanding their own disposition towards conflict and their own conflict style. These issues frame expectations for the self and other for how to behave in a conflict. The second area of concern in educating health care professionals about conflict in teams is to clarify role relationships, expectations for behavior and power differences. Finally, educational experiences should provide alternative strategies for approaching conflict and facilitating conflict resolution. By identifying these issues for team members, different levels of understanding about the conflict process can serve as a catalyst for change.

\subsection{Perceptions about conflict and conflict styles}

Understanding team conflict management requires team members to define conflict using similar terminology and then applying conflict management skills appropriately for group interaction and positive outcome results. Even though 
conflict management begins with individual styles and approaches ${ }^{[13]}$, creating a common approach to conflict resolution and use of communication strategies that work towards collaboration creates a stronger possibility for positive resolutions. The relationship between conflict style and its connection to how one uses communication strategies based on style is supported and described in previous research findings ${ }^{[12,14-16]}$. Individual perceptions in areas such as the use and value of conflict, affects when and how an individual manages conflict. The perceptions we have about conflict are reflective of our conflict style. Conflict communication style is used to describe five basic types of response to conflict in general. First, the avoidant communicator withholds complaints, and withdraws from the conflict process. Second, an accommodator attempts to minimize conflict by focusing on the needs of the other and "gives in" to the wants of the other. Third, an integrating strategy focuses on a desire to collaborate and relies on an open exchange of relevant information. Fourth, a dominant communicator style is competitive, focusing on individual needs, wants and power. Finally, the fifth style is a compromise that involves attempts to negotiate and seek middle ground ${ }^{[17]}$. These styles indicate certain proclivity for using similar conflict tactics in different contexts or with different people ${ }^{[18]}$. In other words, conflict styles are reflective of ways in which we habitually handle disagreements. While this is crucial for individual understanding, it is not the focus of this study. Rather, it is the recognition of the importance of incorporating these ideas into educational training.

\subsection{Social learning theory and conflict}

Social Learning Theory focuses on direct and indirect ways of learning by using self-regulation ${ }^{[19-21]}$. Learning is defined as knowledge acquisition through cognitive processing ${ }^{[20]}$. Specifically, individuals are able to learn by observing others' behavior and are able to regulate behaviors by imagining consequences of behavior ${ }^{[19-22]}$. Using the tenets of this theory, learning is linked to cognition, observation of behavior and an understanding of the consequences of behavior. Educational programs must include these aspects of social learning to increase actual behavioral change. Education of health care professionals about conflict begins, then, with cognition about self-behavior and expectations. Next, educational programs should incorporate that knowledge with more competent conflict communication strategies by using role playing or envisioning positive competent conflict strategies. Finally, the outcome of these activities can be examined in order to understand the consequences of the behavioral change.

A discussion about coping strategies and the role they play in conflict is important in any educational program. Coping is a person's appraisal of their ability to manage demands placed upon them. Cognitive appraisals are "judgments of the implications of the person-environment relationship for one's personal well-being and one's ability to cope with the event” ${ }^{[23]}$. The process is explained using primary and secondary appraisals. Primary appraisals determine the stress in the situation ${ }^{[24]}$. Once an individual decides the environment is stressful, s/he will engage in the process of secondary appraisals. The secondary appraisal determines the level of resources and options required for coping with the situation. When a person determines she or he has the resources to handle the stressor (i.e., perceived ability to cope with the stressor), the situation is less threatening. Conversely, when a person determines the situation as beyond his or her capabilities, the situation is viewed more threatening.

Health care team members appraise conflict and communication as something they should control, especially by those members who are perceived as having more power. However, team conflict facilitation requires communication skills that differ in approach from individual conflict resolution strategies. In essence, the coordination and control of information, such as varying opinions and ideas, which allows for all members to participate, creates new challenges for team members. Therefore, while members recognize the potential for conflict, they may not have the strategies to successfully deal with conflict. As such, members have a heightened awareness but are without the strategies or coping mechanisms to deal with the stress of conflict. Educating health care team members about conflict is one way to enhance team member self-efficacy by increasing coping strategies for team member's behavior during conflict. By identifying strategies and tactics perceived to be useful for engaging in conflict and creating scenarios in which to practice those strategies, interdisciplinary team members become more competent in communicating and resolving team conflict. As a result of the ideas discussed above 
and the link between cognition, observation and understanding consequences of behaviors posed by Social Learning Theory, we pose the following research questions:

RQ 1: What perceptions are held about conflict?

RQ 2: What behaviors do individuals perceive they use during conflict?

RQ 3: What behaviors are perceived to be useful in handling conflict in the health care team?

RQ 4: What communication strategies are perceived to be competent conflict strategies within a team setting?

RQ 5: What are the perceived skills needed to work through team conflict?

\subsection{Communication competency and conflict in teams}

Communication competency and conflict in interdisciplinary health care teams assumes members understand the complexity of expected behaviors, power relationships among team members, the changing nature of knowledge-based needs within the team, increased specialization, overlapping responsibilities of the members, role shifting, territorial behavior and the need for collaboration from individuals with different areas of expertise. Each of these areas creates a multiplex set of evolving relational roles among interdisciplinary team members. The key to providing more positive patient outcomes is the assessment, coordination and control of services among interdisciplinary teams' members. However, little is known about how health care teams communicate ${ }^{[25,26]}$. Competent communication is crucial to teamwork but is often lacking in teams ${ }^{[27]}$. Further complicating interdisciplinary team communication is the communication that takes place outside of the formal meetings or the "backstage" of health care ${ }^{[26]}$.

Communication competence judges the appropriateness and effectiveness of communication ${ }^{[18]}$. During conflict, the ability to communicate appropriately and effectively is tested because of tension between meeting personal goals and expectations with those of other team members. Effectiveness is the way communication is assessed in the accomplishment of goals. The appropriateness of communication looks at the expectations of others. For example, when teaching medical students, faculty expectations concerning problem based learning and how conflict should be handled significantly differs from those of the medical students ${ }^{[28]}$. Competent team communication blends personal (effectiveness) and team (appropriateness) goals. Individual choices about conflict behavior effects team relationships and team outcome goals. It is the perceived competence that mediates the link between conflict behavior and relational outcomes ${ }^{[18]}$. Therefore, understanding the relationship between individual perception about conflict and its link to team conflict strategies is crucial for understanding communication competency in team conflict. These ideas lead the researchers to pose the following research question:

RQ 6: Does an individual's perception of conflict affect their perception of team conflict management strategies?

\section{Methods}

\subsection{Participants}

The participants were members of two undergraduate nursing classes at a large mid-western university. Subjects consisted of sixty-eight undergraduate nursing students who were registered in two nursing courses. Sixty-eight surveys were distributed and sixty- seven surveys were completed for a response rate of $98 \%$. Of the respondents, $83 \%$ were female, $9 \%$ were male and $8 \%$ did not specify that information. Over half of the respondents were older than 22 years of age, with $35.82 \%$ of the respondents over 25 years old, $31.34 \%$ between the ages of $22-25$ years, $13.43 \%$ between the ages of $20-21$, $11.9 \%$ between the ages of $17-19$ years and $8 \%$ missing responses. All respondents were at the undergraduate level so that $37 \%$ of the respondents were first year students, $30 \%$ were second year students, $22 \%$ were third year, and $3 \%$ were fourth year. A total of $8 \%$ of the respondents were missing responses for this question. 


\subsection{Procedure}

After receiving approval from the university's Internal Research Review Board, a random selection of two courses among all the courses offered in the nursing program were chosen to reach the potential respondent pool. In order to increase understanding of the study's purpose, one of the researchers attended one class in each of the two courses to explain the purpose of the study, reinforce voluntary participation, and to describe their rights as potential human subjects, i.e., to refuse to participate in the study, the ability to stop participation at any time and the protection of their privacy. After the initial explanation by the researcher, class members received an open-ended survey questionnaire, which began with an informed consent letter. The letter restated the purpose of the study, provided information on informed consent and the contact information of the researchers for any questions they might have about the study. All participants included in the study agreed to participate and signed the informed consent. Once agreeing to participate, respondents moved on to the open-ended survey questions focusing on their views on conflict, conflict behavior and perceived appropriate conflict strategies in health care teams. Respondents were instructed to have their ideas reflect their personal experiences or thoughts about conflict, how they felt conflict should be handled both personally and in health care teams. To avoid identification of any respondent, both completed and blank surveys were put in sealed envelopes by the participants and returned to the researcher. No participant received extra credit for participating in this study.

\subsection{Measurement}

Previous conflict research was used to identify topic areas for the open-ended questions. The goal of the research was to understand how respondents viewed conflict, identify expected behaviors respondents had for dealing with conflict within health care teams and the respondent's perceived communication competency behaviors during conflict. Previous research examining conflict and communication competencies were used to create initial open-ended questions for the survey ${ }^{[2,12,15,26,27]}$. For example, Conerly \& Tripathi ${ }^{[12]}$ describe filters we use to understand and respond to conflict. The filters include attitudes towards an interaction, expectations for others and our own behavior within interaction, and personal needs during these interactions. Each one of these filters influence conflict behavior. Therefore, the first set of survey questions in this study focused on how these personal filters influence our understanding, expectations and response to conflict.

Long ${ }^{[15]}$ found interdisciplinary team members perceptions of teamwork impacted team member behavior. Results of her study indicated that when roles were not clarified well, there was a lack of communication among various team members often due to power differentials. Long also found that conflicts occurring among team members were mostly due to poor communication. Poor or inadequate communication often occurs when individual communication strategies and tactics differ from expected communication behaviors, i.e., expectancy violation. Therefore, the current study created open-ended questions that focused on perceived communication competencies, perception about the conflict process and expected team member behavior when dealing with conflict.

The final survey contained open-ended questions seeking to identify individual perceptions about conflict, perceived communication competency behavior useful during conflict and perceptions about how team conflict should be managed. The open-ended questions link individual perception about conflict to team behavior and activity.

\subsection{Coding procedures}

Once the surveys were returned to the research team, the responses were transcribed for each question. The second author unitized all open- ended responses; unitizing involves identifying distinct responses that are expressed as a phrase, sentence or paragraph. These procedures have been used in previous research to understand the complex ways in which people use communication ${ }^{[29]}$. The second author used induction techniques to sort all open-ended responses and develop primary categories from the descriptive responses. This method allows for the emergence of categories grounded in the data ${ }^{[30]}$. Next, a second coder (first author) independently coded all the responses to the open-ended questions to be certain 
the categories were mutually exclusive and valid. For all responses, there were 415 phrases that were coded. Agreement was reached on 383 of the phrases for agreement at $92.2 \%$.

\section{Results}

Research question one focuses on general perceptions respondents have about conflict. Sixty-seven respondents produced 90 responses about conflict images. Fifty-one metaphors used imagery to describe how they perceived conflict (see Table 1). The overall imagery used by respondents consisted of war, battle, fighting, brawl, nightmare, big brick wall, closed spaces, collision, and fighting cats. For example, respondents stated, "I picture a war, lots of noise. I think about battling, fighting, and arguing". Another states, "When I think of conflict I usually think about a direct confrontation with someone else or with a problem”. One respondent stated the ideas in terms of medicine, "it is like something that isn't working out, like two meds that don't go together, so it may cause a conflict, with lots of side effects." Finally, another stated, "it is a situation you're in and you don't know what to do to get out of it; like a big brick wall with holes in it that you have to find and break down. It is a war with fighting."

Table 1. Category

\begin{tabular}{lll}
\hline Metaphors & Emotions & Behaviors \\
\hline $\begin{array}{l}\text { War/fighting/battle, Brick wall, } \\
\text { Small/closed spaces, }\end{array}$ & $\begin{array}{l}\text { Distress, anxiety, frustration, anger, } \\
\text { Clashes/Brawls/Nightmare, }\end{array}$ & $\begin{array}{l}\text { crying, yelling/screaming, assertive, } \\
\text { violence/fist fighting, physical and verbal } \\
\text { tension, confusion, hurt, hostility, stress, } \\
\text { abuse, assertive, discussion, confrontation, } \\
\text { orange, black, fire), weapons, fighting cats }\end{array}$ \\
\hline
\end{tabular}

The use of metaphor and symbolism to decipher the speaker's understanding of a concept has a long history. Kenneth Burke ${ }^{[31]}$ applied metaphor as a means to "see" something or to visualize the concept more concretely. We can find examples of Burke's vision in the use of language by respondents that create images such as, "war", "battle" and "fighting cats." Even as one respondent wrote "nightmare" as an example of the meaning of conflict, the respondent also included physiological responses connected to that vision, such as rapid heartbeat, as the extension of the re-called experience.

Table 1 illustrates responses linked to emotional terms regarding perceptions of conflict. Terms such as distress, anxiety, anger, hurt, frustration and stress point to the negative emotional states respondents connect with conflict. Overall, $80 \%$ of the responses are either in the metaphor or emotion category. Clearly, conflict is not perceived positively. Metaphor and imagery, then, are useful tools for discovery of conflict perception and associated behavior connected to that perception.

The perception overall is that conflict is, at the very least, negative and should be avoided. From respondents who imagine conflict negatively, the belief is that engaging in conflict has a poor outcome. These perceptions may lead to avoidant conflict behavior.

RQ 2 asks, “what behaviors do individuals perceive they use during conflict?” This research question takes the generalized ideas found in RQ1 to a more personal level of conflict managing in RQ2. In this case, the depictions were less vivid but more personal. Each respondent's perception of conflict was placed into one of the following categories: conflict perceived as a last resort/least preference, as a negative experience, as a normal/life activity, standpoint, and opportunity.

The categories can be further clarified. The first category of last choice/least preferred means the subject only resorts to engaging in conflict after exhausting all other methods to handle the situation. The negative category means the respondent expects the situation to be a negative experience and others in the situation will act and react badly. In describing their use of conflict, one respondent states, "I don't like it, I usually avoid it if possible. If not possible, it makes me very nervous. It is nonproductive, an ineffective use of time and annoying." The normal activity category refers to conflict being viewed as 
a regular life activity or a normal event so that respondents stated, "conflict is an inevitable opportunity for growth or failure. It is only negative if nothing was learned from it or if negativity comes from it. Conflict can also be positive and desired." Standpoint category refers to the boundary drawn or the position that the subject has taken on a topic or issue. For example, one respondent stated, "conflict is a way to solve problems or a way to keep control over a group of people." Finally, the conflict as opportunity category refers to conflict as an occasion to explore differences of each party in the conflict situation. One respondent stated, “conflict, in the right setting, can help you see things from someone else's view”.

RQ 3 asks, "what behaviors are perceived to be useful in handling conflict in the health care team?” The question focused on generalized behaviors perceived to be useful. Of the 61 different responses received, the majority of responses focused on avoidance behaviors such as, walking away, avoiding the person and avoiding conflict at all costs: "the conflict was at work. I kept it to myself because I'm not in an authoritative position to change the problem." Other responses were descriptions of rational behaviors such as being rational, calm, and think things through. For example one respondent stated, "I made a list of things I didn’t agree with then I thought about the point I wanted to get across. Then I asked for a meeting with the person, we went over the areas we disagree on...." Still another stated, "I tried to rationalize with the person whom I had the conflict with. I tried to prove to them my point of view and why I thought I was right about the problem.” Almost a quarter of the responses focused on talking, openly discussing ideas, and being heard and understood. For example: "I spoke to the people involved. Then I tried to ascertain the reasons for the conflict and ways conflict could be resolved." Finally, some of the responses focused on pre-visualizing or preplanning and rapidly completing the conflict such as solve conflict quickly. For example, "I vented to friends, then gained courage and calmly confronted the person. Compromising seems to work well, meet the other person half way.”

RQ 4 asks, "What communication strategies are perceived to be competent conflict strategies within a team setting?" Six strategies emerged: the need to act professionally, following the chain of command or structural policies and procedures, remaining calm, using listening skills, asking questions, and the recognition that all conflict situations are different. For example, one respondent states”, I think about the best way to handle it and that might involve going to a superior and getting their advice or have them take care of it. Otherwise if it's not serious I handle it myself by speak directly to the other party.”

RQ 5 asks, "What are the perceived skills needed to work through team conflict?"

Of the 63 total responses, most respondents stated that there was a need for "good" interpersonal communication skills/people skills. Other ideas include: listening skills, emotional check/self control, and maintaining a professional demeanor. Some respondents were uncertain what skills would be needed at all. Some responses include: "I think asking questions, being prepared and never doing anything with doubt. Ask, I intend to discuss and resolve conflict; speak, ask questions, ask for help when needed; try to listen and discuss how problems can be resolved; conflict in healthcare should not be ignored; discussion, education.”

Finally, RQ 6 asks, “does an individual's perception of conflict affect their perception of team conflict management strategies?” To address this question, a comparison is made between the respondents' perception of conflict and the respondents' perception of team conflict strategies. Interestingly, most of the individual strategies describe negative behaviors and expectations while the expectation for team conflict assumes professionalism and formalized structural policies and roles. The assumption is that conflict within teams will be alleviated through the use of organizational policies and practices. When personal ways of dealing with conflict are described as a way to resolve team conflict, the strategies are mixed: either negative depictions/avoidance or remaining calm and using professional asking questions is described. Interestingly, respondents' views on how they behave in a conflict covered the continuum from unresolved to resolved conflict situations but with three striking additions. Specifically, almost a third of the respondents said that they did not handle the situation/people well and more than half of the respondents added that emotions, relationships and timing were major factors in whether the result/conclusion of the conflict situation ended well or poorly. 


\section{Discussion}

The purpose of this study was to explore perceptions that respondents have about conflict and how these perceptions impact behavioral expectations for members of health care teams. The outcome of the study is to provide a framework for which nursing educators can develop curriculum focusing on conflict management and communication. There are two outcomes relevant to curricular development for those within the medical profession. First, the results provide an overall view respondents have about conflict and expectations for conflict behavior. Respondents consistently reported strong and negative perceptions about the conflict process. Specifically, they reported negative perceptions about engaging in conflict, negatively evaluated personal conflict behavior, and often felt dissatisfied with conflict outcomes. Negative perceptions about conflict engagement are not uncommon ${ }^{[32]}$. Conflict in the workplace can lead to a decrease in productivity, dissatisfaction at work, and impact morale ${ }^{[33]}$. When conflict is not managed professionally, it may lead to decreases in information exchange and poor communication ${ }^{[34]}$. Indeed, these negative perceptions impact the angst health care workers feel as a member of an interdisciplinary team. For example, health care workers identified trust and conflict management as key concerns for working in health care teams ${ }^{[35]}$. These concerns are not alleviated over time because communication skills do not improve with clinical experience alone ${ }^{[8]}$.

Clearly, negative perceptions of conflict need to be reframed positively. There is a need to educate those training for health professions to understand conflict as a way to improve overall decision making, increase innovation in the workplace, and create a culture of loyalty and innovation ${ }^{[34,36,37]}$. Thus, curricular development should transform current conflict perceptions by breaking down negative misconceptions in order to build a new understanding about conflict. Understanding that conflict is a normal process in teams, that conflict is connected to emotion, and that learning communication conflict skills can improve outcomes for the process will improve team communication and dynamics.

Re-conceptualizing conflict requires having a strong motivation to change. One way to strengthen this motivation is to illustrate the inherent nature of conflict in teams and that team members are reliant on each other to complete a task. The reliance on all team members to deliver quality patient care provides the motivation for change. Because team members are a diverse group, curricular development should include discussion of gender and cultural variations in how people perceive conflict as well as how they enact communication behavior within conflict. Next, communication strategies and skills should be incorporated and practiced through role playing scenarios relevant to health care teams.

To achieve success in reframing conflict perceptions, common terminology for discussing conflict is necessary. Several resources are available to nursing curriculum planners and faculty. Hocker \& Wilmot ${ }^{[38]}$ provide clear definition of interpersonal conflict, "Conflict is an expressed struggle between at least two interdependent parties who perceive incompatible goals, scarce resources, and interference from others in achieving their goals” (p. 13). Their definition provides a foundation for understanding conflict with perception at the core. In interpersonal conflicts, people react as though there are genuinely different outcome goals that each person has within the conflict. Often individuals perceive that there is not enough of a resource they seek so that in order to gain what they want as an outcome, the other person must give up or lose. It is in "sorting out what is perceived and what is interpersonally accurate forms the basis of conflict analysis" (p.13). Taking the ideas further, Burke ${ }^{[31]}$ and Morgan ${ }^{[39]}$ provide multiple examples of the perception of conflict through the use of imagery and metaphors. Metaphors provide a visual way to communicate understanding about conflict to the self and others ${ }^{[39]}$. These metaphors provide a way to compare conflict with characteristics of other unrelated concepts in order to re- frame our perception and experience of the conflict process.

Bandura's ${ }^{[19-22]}$ Social Learning Theory guides nursing faculty in creating explanations of communication phenomena in stressful conflict situations and provides a frame to discuss conflict perceptions. Specifically, the learning process is a series of judgments about the conflict situation and assessments of coping mechanisms for conflict. Based on the current study, respondents tended to prejudge conflict as a negative experience and as something to avoid. The respondents also negatively assessed their ability to cope. Thus, their final assessment would be flight. Re-learning this concept as positive vs. negative would require reinforcement where communication strategies would provide constructive and positive ways 
to cope in multiple conflict scenarios. Imagery and the use of metaphors of conflict can offer individuals the visual side of communication to understanding the process ${ }^{[39]}$.

The second area of interest identified in this study focuses on expected conflict behaviors and communication strategies for members in a health care team. There seems to be a disconnect between how respondents perceive their current behavior and what they expect their behavior to become once they are a member of a health care team. The assumption is that organizations will provide a venue to work through the conflict instead of the individuals engaged in conflict assuming responsibility for conflict resolution. For example, in attempting to solve a conflict dilemma in the workplace, respondents reported that they look to a formal, structural entity to resolve team conflict issues. This finding parallels other research ${ }^{[15]}$ where team members were reluctant to share difficulties and conflicts that focused on work related issues.

Personal conflict styles can be used to explain the difference between personal conflict management strategies and expected conflict management strategies in the workplace. Conflict style impacts behavior based on cooperation and commitment ${ }^{[12]}$. As a member of a health care team, cooperation and commitment among members is a necessary component in making decisions and providing quality care. In recalling how they handled their last conflict, over a third of the respondents felt they handled the conflict poorly. Respondents also stated that they relied on negative strategies such as walking away, silent treatment, giving in, yelling/screaming, avoiding and venting. These behaviors are examples of the avoidant communicator conflict style. The avoidant communicator will withdraw from engaging in conflict and seek out an authority figure in the workplace who has conflict management skills. The expectation is that formal processes and procedures are in place ${ }^{[13]}$. In the current study, the respondents clearly identified expectations for formal conflict resolution processes within health care teams using terms such as "professionally," "chain of command," and "look to the supervisor” to describe ways in which conflict would be resolved in health care teams.

The expectation for formal conflict resolution structures to be part of formal practices in health organizations highlights other areas for curricular development. The development should include interpersonal skills to improve interactions with others ${ }^{[40]}$. A common thread through the survey responses was the need to improve communication competencies. Respondents stated good interpersonal communication skills are essential to building better conflict management techniques. However, in recalling how they handled their last conflict, $34 \%$ felt they handled the conflict poorly, while 33\% stated they handled the conflict using negative strategies such as walking away, silent treatment, giving in, yelling/ screaming, avoiding and venting. Designing an educational program to include positive communication strategies as a model for health care teams leads to a blending of individual strengths and areas of expertise.

Finally, interdisciplinary team members gain trust and confidence in each other when they are able to successfully work together. This trust increases over time so that as success increases, trust also increases. Trust also increases how team members integrate services and improve negotiation of conflict ${ }^{[26]}$. By providing the communication tools for dealing with conflict and by educating nursing students about conflict, the ability for these students to segway successfully into a health care team setting increases.

\subsection{Limitations}

There are several limitations in the current study. The goal was to identify a baseline of understanding about conflict for educating nursing students. However, the respondents consisted of nursing students with limited experience working on a health care team. Therefore, future research should broaden the respondent pool to include members of health care teams. The second outcome was to understand perceived successful conflict strategies and communication behaviors. Further research with current interdisciplinary team members would provide a clearer understanding of these successful behaviors. Highlighting conflict behaviors as they become salient in the decision making process and in coordinating patient care could then be incorporated into curricular development. 
While this study was conducted in the Midwest, it may be useful to expand the study to include other geographic areas. Perception of conflict and expected conflict behavior are influenced by culture and group identity. Attempts to provide greater variation in the subject pool could be increase generalizability of the results.

\subsection{I mplications}

Integrative health care teams positively affect patient outcomes and decision making about patient care and treatment. However, this process may also lead to conflict. The realization that conflict is inherent with interdisciplinary team collaboration is the first step in understanding the process ${ }^{[41,42]}$.

Communication strategies and conflict management styles and expectations for conflict behavior impact decision making in teams. Specifically, groups that develop integrative conflict management styles make more effective decisions than groups that use confrontation and avoidance styles ${ }^{[43]}$. Further, communication and conflict are positive and significant predictors of team cohesion and team effectiveness ${ }^{[44]}$. Clearly, conflict strategies alter the way in which teams function and attain goals. Therefore, training team members to learn more competent ways of handling conflict within the team should positively influence the decision-making outcomes of the team.

Nursing education that includes conflict management curriculum will provide future nurses with the knowledge and skills needed to approach, manage and alleviate conflict. Identifying perceptions about competent communication strategies for dealing with conflict in health care teams clarifies expectations held for team member behavior. How health care professionals perceive conflict and understand their own communication strategies for dealing with conflict affects how they approach conflict in health care teams. By training health care professionals about the conflict process, competent conflict strategies and behavior, the team members should achieve more effective outcomes for dealing with conflict, which leads to more effective team practices, and outcomes.

Education including knowledge, understanding, behavior, and coping mechanisms for team members in conflict will serve several functions. First, it should increase positive appraisals about conflict situations. Second, the educational experience allows for recall knowledge and skills specific to managing conflict lead to more positive appraisals of conflict. Third, the behavioral component increases the understanding and development of conflict facilitation skills.

\section{References}

[1] Cott, C. Structure and meaning in multidisciplinary teamwork. Sociology of Health and Illness.1998; 20(6): 848-873. http://dx.doi.org/10.1111/1467-9566.00132

[2] Cooke, C. Reflections on the health care team: My experiences in an interdisciplinary program. The Journal of the American Medical Association. 1997; 277(13): 1091-1092. http://dx.doi.org/10.1001/jama.27.13.1091

[3] McHugh, M., West, P., Assatly, C., Duprat, L., Niloff, J., Waldo, K. Establishing an interdisciplinary patient care team: Collaboration at the bedside and beyond. Journal of Nursing Administration. 1996; 26(4): 21-27. http://dx.doi.org/10.1098/00005110-199604000-00009

[4] Langhorne, P., Williams, B., Gilcrest, W. \& Howe, K. Do stroke units save lives? The Lancet. 1993; 342(8868): 395-398. http://dx.doi.org/10.1016/0140-6736(93)92813-9

[5] Baldwin, Jr., D.C., Royer, J., \& Edinberg, M. Maintenance of health care teams: Internal and external dimensions. Journal of Interprofessional Care, Supplement 1. 2007; 21: 38-51. http://dx.doi.org/10.1080/13561820701580032

[6] McNeil, K.A., Mitchell, R.J., \& Parker, V. Interprofessional practice and professional identity threat. Health Sociology Review. 2013; 22(3): 291-307. http://dx.doi.org/10.5172/hesr.2013.22.3.291

[7] Masterson, A., Maslin-Prothero, S., \& Ashby, S. Using interprofessional education to support intermediate care. Nursing Older People. 2013; 25(2): 20-24. PMid:23581221 http://dx.doi.org/10.7748/nop2013.03.25.2.20.e408R1

[8] Sargeant, J., MacLeod, T., \& Murray, A. An interprofessional approach to teaching communication skills. Journal of Continuing Education in the Health Professions. 2011; 31(4): 265-267. http://dx.doi.org/10.1002/chp.20139

[9] Martin, M.M. \& Rubin, R.B. Development of a communication flexibility measure. Southern Communication Journal. 1994; 59(2): 171-178. http://dx.doi.org/10.1080/10417949409372934 
[10] Porter-O’Grady, T. Embracing conflict: Building a healthy community. Health Care Management Review. 2004; 29 (3): $181-187$. http://dx.doi.org/10.1097/00004010-200407000-00003

[11] Coleman, M.T., Roberts, K., Wulff, D., van Zyl, R. \& Newton, K. Interprofessional ambulatory primary care practice-based educational program. Journal of Interprofessional Care. 2008; 22(1): 69-84. http://dx.doi.org/10.1080/13561820701714763

[12] Conerly, K. \& Tripathi, A. What is your conflict style? Understanding and dealing with your conflict style. The Journal for Quality and Participation. 2004; 27: 16-20.

[13] Lumsden, G. \& Lumsden, D. Communicating in groups and teams.(3rd Ed.). Belmont, CA: Wadsworth; 2000.

[14] Conrad, C. Communication in conflict: style strategy relationships. Communication Monographs. 1991; 58: $135-155$.

[15] Long, S. Primary health care team workshop: Team members’ perspectives. Journal of Advanced Nursing. 1996; $23(5)$ : 935-41. PMid:8732520 http://dx.doi.org/10/1046/j.1365-2648.1996.10911.x

[16] McKinney, B.C. \& Kelly, L. The relationship between conflict message styles and dimensions of communication competence. Communication Reports. 1997; 10, 2, 185-195.

[17] Rahim, M.A. A measure of styles of handling interpersonal conflict. Academy of Management Journal. 1983; 26: 368-376. PMid:10263067 http://dx.doi.org/10.2307/255985

[18] Cupach, W. \& Canary, D. Competence in interpersonal conflict. NYC, NY: McGraw-Hill, 1997.

[19] Bandura, A. Social learning theory. Oxford, England: Prentice-Hall, 1977.

[20] Bandura, A. Social foundations in thought and action. Englewood Cliffs, NJ: Prentice-Hall, 1986.

[21] Bandura, A. Social cognitive theory of self-regulation (Special Issue: Theoriesof Cognitive Self-Regulation). Organizational Behavior and Human Decision Making Processes. 1991; 50(2): 248-290. http://dx.doi.org/10.1016/0749-5978(91)90022-L

[22] Bandura, A. \& Cervone, D. Differential engagement of self-reactive influences in cognitive motivation. Organizational Behavior and Human Decision Making Processes. 1986; 38(1): 92-114. http://dx.doi.org/10.1016/0749-5978(86)90028.2

[23] Dillard, J., Kinney T., \& Cruz, M. Influence, appraisals and emotions in close relationships. Communication Monographs. 1996; 63(2): 105-131. http://dx.doi.org/10.1080/03637759609376382

[24] Lazarus, R. \& Folkman, S. Stress, appraisal and coping. NYC, NY: Springer Publishing. 1984.

[25] Opie, A. Thinking teams/thinking clients: Knowledge-based teamwork. NYC, NY: Columbia University Press, 2000.

[26] Ellingson, L. Interdisciplinary health care teamwork in the clinic backstage. Journal of Applied Communication Research. 2003; 31(2):93-117. http://dx.doi.org/10.1080/0090988032000064579

[27] Gage, M. From independence to interdependence: Creating synergistic healthcare teams. Journal of Nursing Administration. 1998; 28(4):17-26. http://dx.doi.org/10.1097/00005110-199804000-00006

[28] Devi, V., Pallath, V., Lim, B., Wue, C., Mun, C.K., Adward, J.A. et al. Perceptions regarding the quality of group interactions during brain storming session of problem based learning at Melaka Manipal Medical College (Manipal Campus), India. Education in Medicine Journal. 2012; 4: 19-25. http://dx.doi.org/10.5959/eimj.v4i2.11

[29] Wanzer, M. B., Booth-Butterfield, M. \& Booth-Butterfield, S. “If we didn’t use humor, we’d cry.” Humorous coping communication in health care settings. Journal of Health Communication. 2005; 10(2): 105-125. http://dx.doi.org/10.1080/10810730590915092

[30] Strauss, A., \& Corbin, J. (2nd Ed.). Basics of qualitative research: Techniques and procedures for developing grounded theory. Thousand Oaks, CA: Sage, 1998.

[31] Burke, K. The philosophy of literary form. Berkley, CA: University of CA Press, 1973.

[32] Robbins, S. P. \& Judge, T. A. Organization behavior (15th Ed.). Newark, NJ: Pearson Education, Inc, 2013.

[33] Masters, M. F. \& Albright, R. R. The complete guide to conflict resolution in the workplace. New York, NY: American Management Association, 2002.

[34] Stack, L. Conflict in the workplace: Conflict can be positive and productive. 2005. Available from: http://www.aviationpros.com/article/10385718/conflict-in-the-workplace-conflict-can-be-positive-and-productive

[35] Gagliardi, K., Xamin, J., Harrison, L.J., Ditomasso, J., O’Hoski, P., \& Heddle, N.M. Team development project in an academic transfusion medicine service. Transfusion. 2001; 41(9): 129S- 130S. American Association Blood Bank.

[36] Adams, D. \& Media, D. Positive and negative consequences of conflict in organizations. 2013.

[37] Baron, R.A. Positive effect of conflict: A cognitive perspective. Employee Responsibilities and Rights Journal. 1991; 4(1). http://dx.doi.org/10.1007/BF01390436

[38] Hocker, J.L. \& Wilmot, W.W. (9th Ed.) Interpersonal conflict. NYC, NY: McGraw-Hill. 2014.

[39] Morgan, G. Images of organization. Thousand Oaks, CA: SAGE Publications. 2006.

[40] Abramson, J.S. \& Mizrahi, T. When social workers and physicians collaborate: Positive and negative interdisciplinary experiences. Social Work. 1996; 41(3): 270-281. Available from: http://search.ebscohost.com/login.aspx?direct=true\&db=aph\&AN=9605021449\&site=ehost-live PMid:8936083 
[41] Greer, L., Saygi, O, Aaldering, H., \& deDreu, C. Conflict in medical teams: Opportunity or danger? Medical Education. 2012; 46(10): 935-942. http://dx.doi.org/10.1111/j.1365-2923.2012.04321x

[42] Maxwell, L., Odukoya, O.K., Stone, J.A., \& Chui, M.A. Using a conflict conceptual framework to describe challenges to coordinated patient care from the physicians' and pharmacists' perspective. Research in Social \& Administrative Pharmacy. (No vol. or no.). 2013. http://dx.doi.org/10.1016/jsapharm.2013.12.002

[43] Kuhn, T. \& Poole, M.S. Do conflict management styles affect group decision making? Human Communication Research. 2000; 26(4): 558-591. Available from: http://search.ebscohost.com/login.aspx?direct=true\&db=aph\&AN=3743749\&site http://dx.doi.org/10.1111/j.1468-2958.2000.tb00769.x

[44] Temkin-Greener, H., Gross, D., Kunitz, S. \& Makumel, D. Measuring interdisciplinary team performance in a long-care setting. Medical Care. 2002; 42: 472. http://dx.doi.org/10.1097/01.mir.0000124306.28397.e2 